\title{
DISSOLUTION RATE OF PURE CaO AND INDUSTRIAL LIME IN CONVERTER SLAGS*
}

\author{
Elizaveta Cheremisina ${ }^{1}$ \\ Johannes Schenk ${ }^{2}$ \\ Ludwig Nocke ${ }^{3}$ \\ Alexander Paul ${ }^{4}$ \\ Gerald Wimmer ${ }^{5}$
}

\begin{abstract}
In steelmaking process lime serves as flux. Rapid lime assimilation and slag formation of the desired composition have a significant effect on the refining reactions. It is important to know the rate limiting step of lime dissolution to control and improve the converter process. Kinetics of pure $\mathrm{CaO}$ and industrial lime dissolution in model slag has been studied in the range of temperatures $1300-1600^{\circ} \mathrm{C}$. Lime samples were prepared in cylinder form and immersed in the melt for predetermined time. Considering the total mass balance of $\mathrm{CaO}$ in the slag and linear dimensions of lime samples, mass transfer coefficients were derived. Diffusion coefficients were calculated under conditions of non-stationary diffusion. The derived activation energy of less than $200 \mathrm{~kJ} / \mathrm{mol}$ indicates that diffusion is the limiting step in the process of lime-dissolution in slag.
\end{abstract}

Keywords: Diffusion coefficient; dissolution kinetics; lime dissolution; steel slag.

Dr.mont., Postdoctoral researcher, K1-Met, Linz, Austria

Professor, Head of the Chair of Ferrous metallurgy, Montanuniversitaet Leoben, Austria.

Dipl.-Ing., Research engineer, Voestalpine Stahl GmbH Linz, Austria.

Dipl.-Ing., Research engineer, Voestalpine Stahl Donawitz GmbH, Austria.

Dr.-Ing., Vice President Converter Steelmaking, Primetals Technologies GmbH, Linz, Austria. 


\section{INTRODUCTION}

In steelmaking process, liquid slag saturated with $\mathrm{CaO}$ and $\mathrm{MgO}$ is required to promote effective refining reactions and refractory lining protection. Slag serves as an essential refining agent and, thus, the desired composition and properties of slag influence process efficiency up to a great extent. Consequently, the rate of flux assimilation by slag phase has a crucial role. The prolongation of the refractory lining of the converter vessel also contributes to the process productivity.

In the research work presented in this paper dissolution kinetics of pure $\mathrm{CaO}$ and industrial lime in steel slags has been investigated. The determination of rate-limiting step in the process of $\mathrm{CaO}$ and $\mathrm{MgO}$ dissolution in the melt has been carried out as an integral part of kinetic study.

For several decades, the diffusion kinetics in steelmaking process has been studied by many researchers and remains one of the most challenging experimental tasks. $[1,2,3]$

Kinetic model based on experimental data has been applied in this work to describe the rate of heterogeneous process of lime dissolution in slag melt. Mass transfer and diffusion coefficients were determined in high temperature experiment.

\section{MATERIAL AND METHODS}

To investigate the dissolution rate of pure $\mathrm{CaO}$ and industrial lime, model slag with the following components was prepared: $20 \% \mathrm{CaO}, 35 \% \mathrm{SiO}_{2}, 45 \% \mathrm{FeO}$. The given slag was chosen to simulate the beginning of the blowing process. The chemical and phase composition of industrial BOF slag, conducted by the RFA analysis is presented in (Table 1):

Table 1. The composition of industrial BOF slag

\begin{tabular}{|cc|}
\hline LD slag & Composition, wt \% \\
\hline $\mathrm{Fe}$ & $18.46-24.16$ \\
\hline $\mathrm{Al}_{2} \mathrm{O}_{3}$ & $1.74-2.05$ \\
\hline $\mathrm{CaO}$ & $38.73-46.68$ \\
\hline $\mathrm{P}_{2} \mathrm{O}_{5}$ & $1.13-1.21$ \\
\hline $\mathrm{SiO}_{2}$ & $11.08-11.09$ \\
\hline $\mathrm{TiO}_{2}$ & $0.21-0.34$ \\
\hline $\mathrm{MnO}$ & $5.96-6.55$ \\
\hline $\mathrm{Cr}_{2} \mathrm{O}_{3}$ & $0.41-0.49$ \\
\hline $\mathrm{MgO}$ & $5.50-6.54$ \\
\hline $\mathrm{S}$ & $0.04-0.07$ \\
\hline
\end{tabular}

The composition of industrial lime is presented in (Table ):

Table 2. The composition of industrial lime

\begin{tabular}{|cc|}
\hline Composition & wt \% \\
\hline $\mathrm{MgO}$ & 2 \\
\hline $\mathrm{CaO}$ & $96-97 \%$ \\
\hline Other & 1 \\
\hline
\end{tabular}

Samples from pure $\mathrm{CaO}$ and lime were prepared in the form of cylinders (with d $22-24 \mathrm{~mm}, \mathrm{~h} 7-10 \mathrm{~mm}, \rho 3 \mathrm{~g} / \mathrm{cm}^{3}$ and mass of $1.5 \mathrm{~g}$ ) using press machine with the 
load of 7 tons per $\mathrm{cm}^{2}$. Cylinder form allowed estimation of sample's geometry change after the dissolution test.

Model slag was prepared from calcium, silicon and iron (II) oxides. Industrial slag used in this work was provided by Voestalpine Linz GmbH.

Prior the dissolution test, slag sample with mass of $2 \mathrm{~g}$ in quartz crucible was premelted in high temperature vertical furnace Gero (HTRV type) under inter gas atmosphere. Quartz crucibles were demonstrated to be inert experimentally for the given slag systems in the range of temperatures of $1300-1600^{\circ} \mathrm{C}$. The detailed procedure including mass balance of slag was reported previously. [4]

After reaching the desired process temperature $1300-1600^{\circ} \mathrm{C}$ slag was held in the furnace for $30 \mathrm{~min}$ to ensure complete melting. $\mathrm{CaO} /$ lime sample was heated up as well to minimize thermal bouncy.

Samples of pure $\mathrm{CaO} / \mathrm{lime}$ were immersed in the molten slag in the range of temperatures $1300-1600^{\circ} \mathrm{C}$ and after a predetermined time removed from the melt. Mass of samples and change in geometrical parameters was precisely measured after cooling.

Quenched slag was extracted from crucible by breaking. X-ray fluorescent spectrometer PANalytical Epsilon 3 was utilized to determine the concentration of $\mathrm{CaO}$ and $\mathrm{MgO}$ in slag.

Mathematical model based on the compositional changes in slag, $\mathrm{CaO}$ and $\mathrm{MgO}$ concentrations and changes in geometrical parameters of samples, was used in this work to calculate mass transfer coefficients.

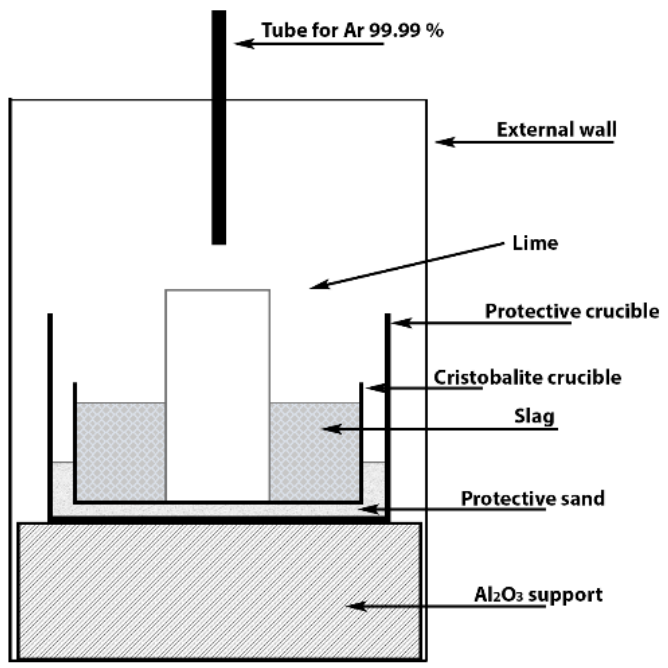

Figure 1. Experimental setup.

\subsection{Mass transfer coefficient determination}

Lime dissolution in steel slag, as any heterogeneous process, consists of a few stages: the delivery of the reagent to the interface, diffusion through solid matrix, chemical reaction, diffusion of product through the solid matrix, mass transfer of the component away from the interface.

In this paper, mass transfer coefficient of lime dissolution was calculated using kinetic model, which considers the total mass balance of the dissolving solid body:

$$
-\frac{d \mathrm{M}_{s o l}}{d t}=\frac{k_{(\mathrm{CaO})} \cdot\left\{(\mathrm{CaO} \%)_{s a t}-(\mathrm{CaO} \%)\right\} s \cdot \rho_{l i q}}{(\mathrm{CaO} \%)_{s o l}-(\mathrm{CaO} \%)}
$$


Where $-\frac{d(\mathrm{CaO})}{d t}$ is mass of dissolved $\mathrm{CaO}, \mathrm{t}$ is time, $\mathrm{s} ;(\mathrm{CaO})_{\text {sat }}$ is saturation concentration of $\mathrm{CaO}$ in slag, $(\mathrm{CaO})$ is concentration of $\mathrm{CaO}$ in the bulk slag; $\mathrm{S}$ is the surface of the sample, $k_{(\mathrm{CaO})}$ is the mass transfer coefficient, $\mathrm{cm} / \mathrm{s}$.

In the experimental studies of mass transfer processes an effective mass transfer coefficient is often used, because it reflects some of the average properties of the diffusion boundary layer, in which the main change in the concentration of the substance takes place.

\section{RESULTS AND DISCUSSION}

\subsection{Dissolution behavior of pure $\mathrm{CaO}$}

As a first step, the dissolution of pure $\mathrm{CaO}$ in model slag $\left(20 \% \mathrm{CaO}, 35 \% \mathrm{SiO}_{2}\right.$, $45 \% \mathrm{FeO}$ ) was carried out. It is shown in (Figure 2) that the $\mathrm{CaO}$ content in slag increases with time. After time interval of 150-160 seconds there is no change in the amount of the dissolved $\mathrm{CaO}$. It characterizes the saturation of slag with calcium oxide. Concentration of calcium oxide in the slag phase at $1300^{\circ} \mathrm{C}$ is $46-47 \%, 50-51 \%$ at $1400^{\circ} \mathrm{C}$ and $54-55 \%$ at $1500^{\circ} \mathrm{C}$ which is close to the theoretic saturation.

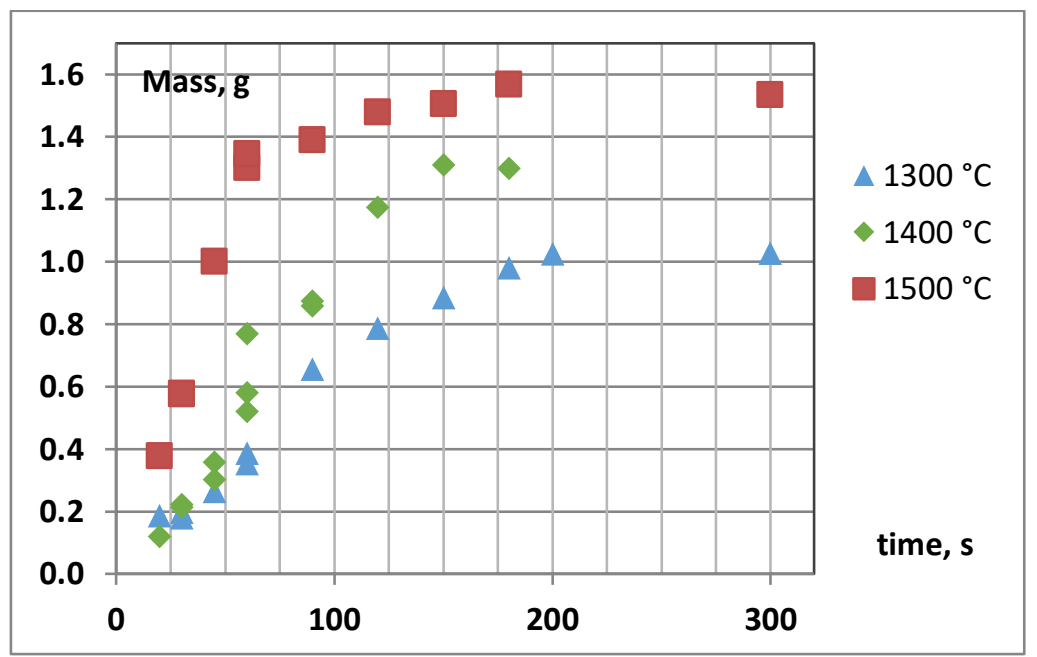

Figure 2. Evolution of mass of the dissolved pure $\mathrm{CaO}$ sample with time.

With the increasing concentration of $\mathrm{CaO}$ in the slag phase the dissolution rate of samples drops (see Figure 3), assuming the decrease in the concentration gradient $(\mathrm{CaO} \%)_{s a t}-(\mathrm{CaO} \%)$, as the main driving force for the dissolution. 


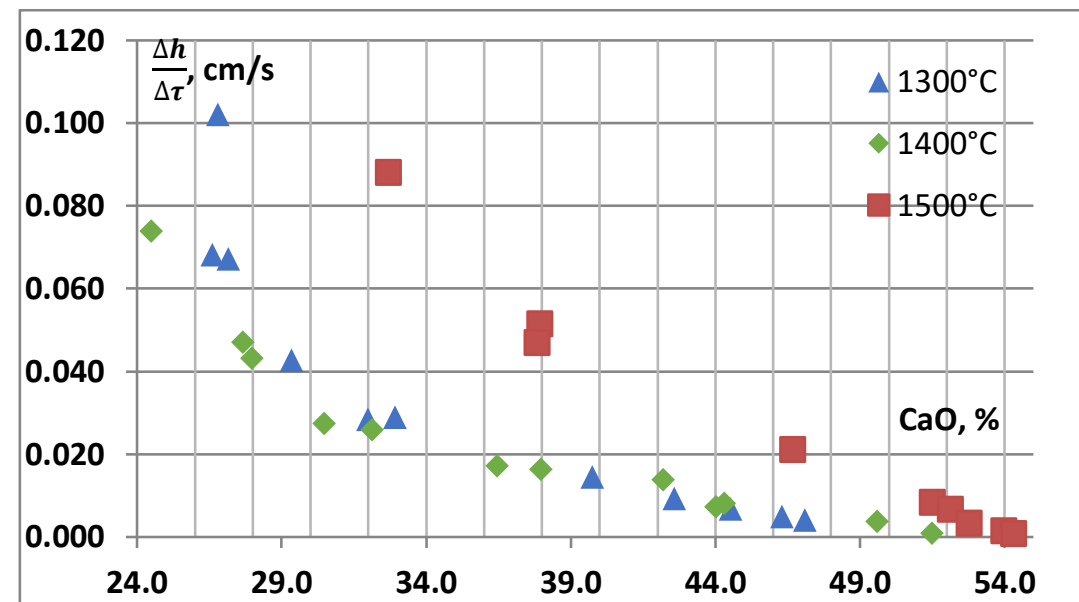

Figure 3. The dependence of the linear rate of $\mathrm{CaO}$ samples dissolution on the saturation of slag with calcium oxide.

Mass transfer coefficients of $\mathrm{CaO}$ dissolution in the model slag were derived using the experimental data and the kinetic (Equation 1).

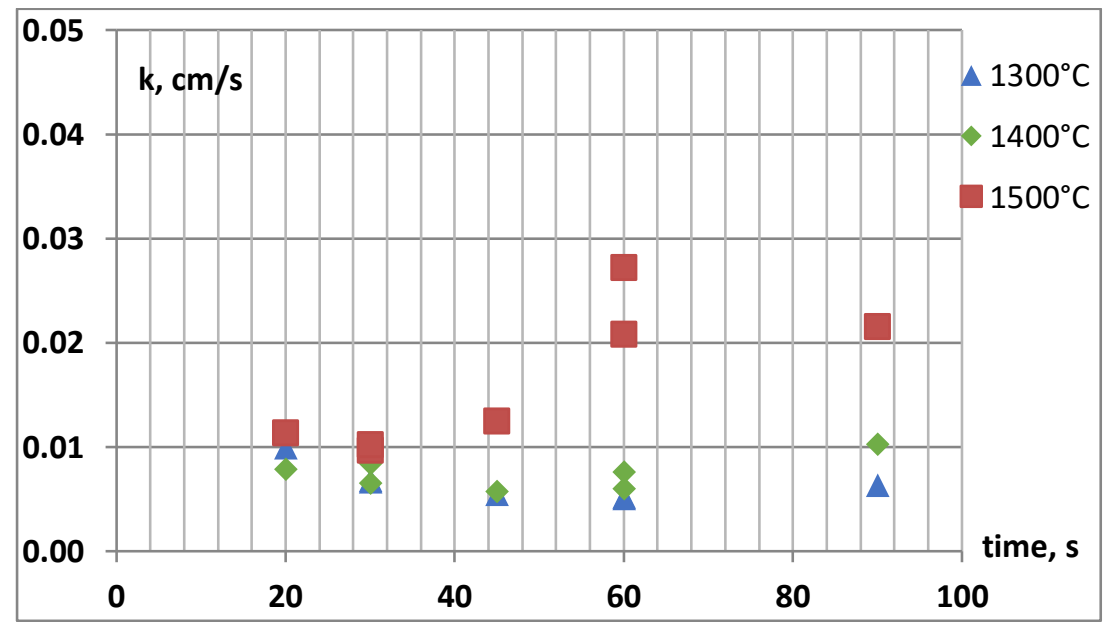

Figure 4. The dependence of the mass transfer coefficient values of $\mathrm{CaO}$ dissolution in model slag on the dissolution time.

According to the results derived, in the dissolution process of $\mathrm{CaO}$ in model slag the mass transfer coefficient raises up to certain value with the decreasing sample size as the dissolution progresses.

Calculated average effective $\mathrm{k}$ values are: $0.0066 \pm 0.0007 \mathrm{~cm} / \mathrm{s}$ at $1300^{\circ} \mathrm{C}$, $0.0078 \pm 0.0009 \mathrm{~cm} / \mathrm{s}$ at $1400^{\circ} \mathrm{C}$ and $0.0162 \pm 0.0011 \mathrm{~cm} / \mathrm{s}$ at $1500^{\circ} \mathrm{C}$.

The derived apparent activation energy denoted the diffusion limiting step in the process of $\mathrm{CaO}$ dissolution with the value of $71.5 \pm 8.6 \mathrm{~kJ} / \mathrm{mol}$

As the next step, dissolution behavior of pure $\mathrm{CaO}$ in the industrial BOF slag has been investigated. The composition of BOF slag is presented in (Table 1). The evolution of mass of the dissolved sample with time is presented in (Figure 5). It is worth mentioning, that time interval until saturation has increased up to 300-350 seconds in comparison with model slag system. 


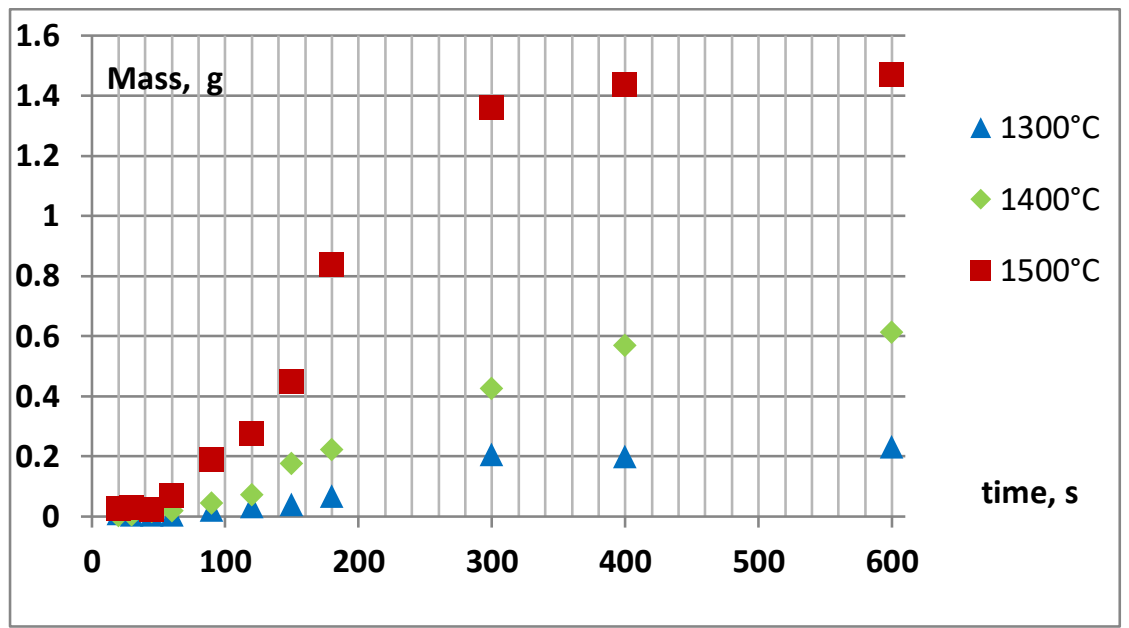

Figure 5. Evolution of mass of the dissolved $\mathrm{CaO}$ sample with time.

The effective saturation concentration of calcium oxide in the slag is $47-48 \%$ at $1300^{\circ} \mathrm{C}, 54-55 \%$ at $1400^{\circ} \mathrm{C}$ and $65-66 \%$ at $1500^{\circ} \mathrm{C}$. As it is evident from the experiment with a contact time above 300 seconds that the dissolution of $\mathrm{CaO}$ samples does not progress which characterizes the equilibrium state of the system.

The relation between the linear rate of sample's dissolution $\frac{\Delta h}{\Delta \tau}$ and the saturation concentration of $\mathrm{CaO}$ in slag indicates the diffusion regime of $\mathrm{CaO}$ dissolution process (see Figure 6), similar to that in the experiment with the model slag.

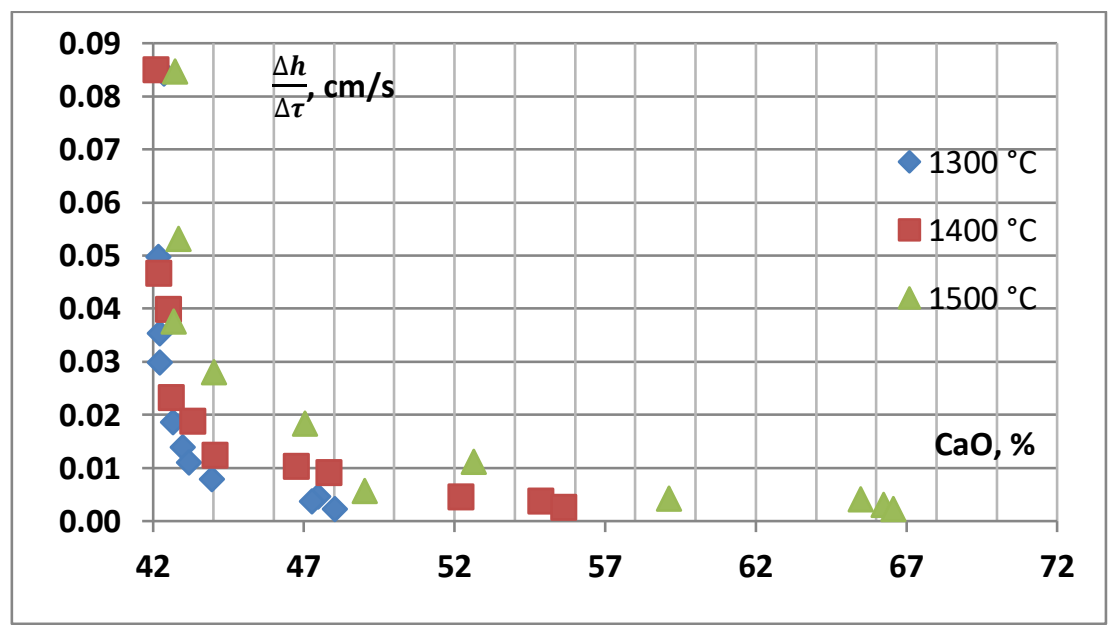

Figure 6. The dependence of the dissolution rate of $\mathrm{CaO}$ samples on the calcium oxide concentration in slag.

The mass transfer coefficient values of $\mathrm{CaO}$ dissolution in industrial slag calculated on the basis of the experimental data are presented in (Figure 7). 


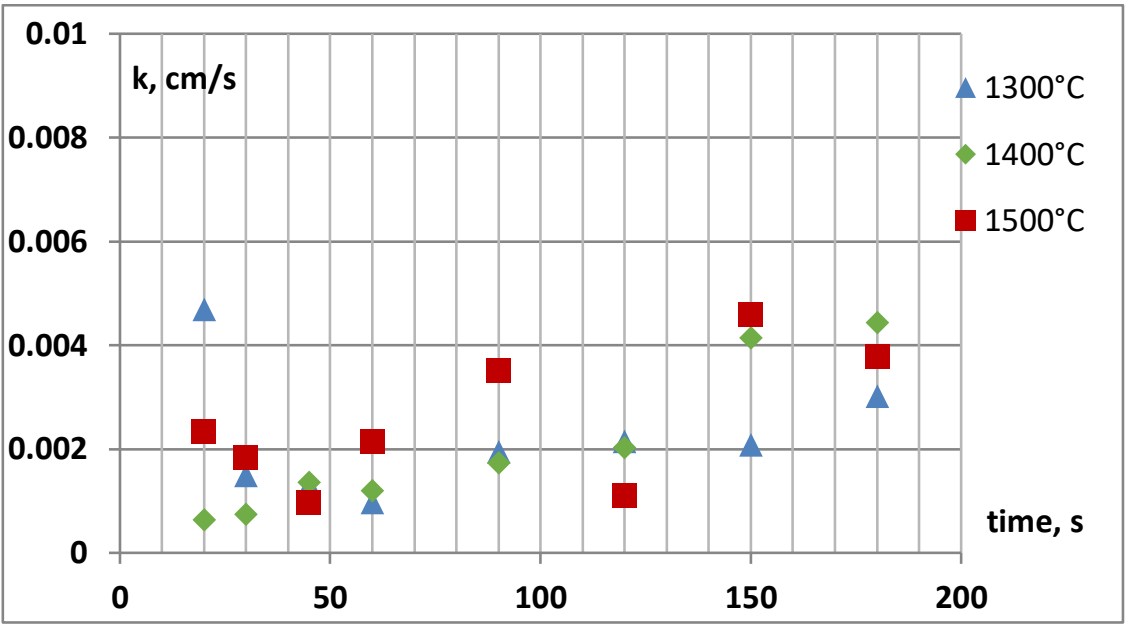

Figure 7. The dependence of the mass transfer coefficient values of $\mathrm{CaO}$ dissolution in industrial slag on the dissolution time.

Calculated average effective values of $\mathrm{k}$ for the industrial slag system: $0.0022 \pm 0.0004$ $\mathrm{cm} / \mathrm{s}$ at $1300^{\circ} \mathrm{C}, 0.0030 \pm 0.0006 \mathrm{~cm} / \mathrm{s}$ at $1400^{\circ} \mathrm{C}$ and $0.0053 \pm 0.0008 \mathrm{~cm} / \mathrm{s}$ at $1500^{\circ} \mathrm{C}$ accordingly.

Solid compounds such as dicalcium silicate formed between industrial slag and calcium oxide inhibit the dissolution process. $[4,5]$ This is the reason for lower values of $\mathrm{CaO}$ mass transfer coefficients in the industrial slag compared to model slag. The value of the apparent activation energy of the dissolution process of calcium oxide in the industrial slag is $70.6 \pm 8.1 \mathrm{~kJ} / \mathrm{mol}$.

In steelmaking processes, industrial lime is used instead of pure calcium oxide, therefore in this work kinetics of technical lime dissolution in model slag was also investigated.

\subsection{Dissolution behavior of industrial lime}

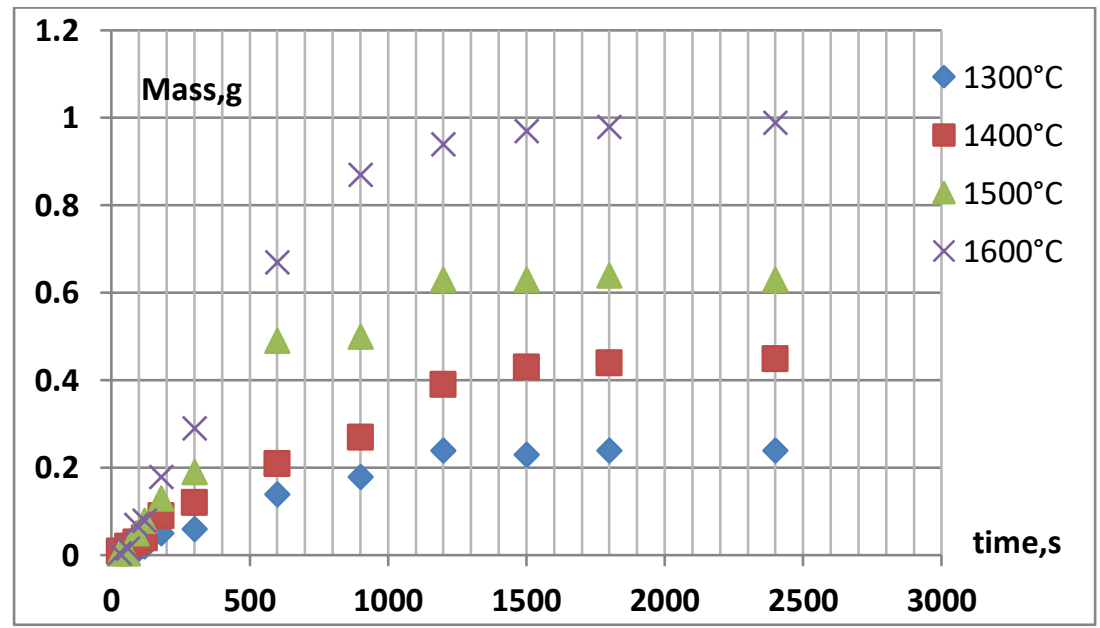

Figure 8. Evolution of mass of the dissolved lime sample with time.

As it is observed in the experiment with a contact time of more than 800 seconds there is no change in the linear dimensions of lime samples which was determined as slag saturation.

The effective saturation concentration of calcium oxide in the slag phase at $1300^{\circ} \mathrm{C}$ is $28.3 \%, 34.3 \%$ at $1400^{\circ} \mathrm{C}, 38.6 \%$ at $1500^{\circ} \mathrm{C}$ and 45.8 at $1600^{\circ} \mathrm{C}$. In comparison with pure $\mathrm{CaO}$, industrial lime requires longer time for dissolution and slag saturation. 
Furthermore, the amount of lime sample dissolved is relatively lower than that of pure $\mathrm{CaO}$.

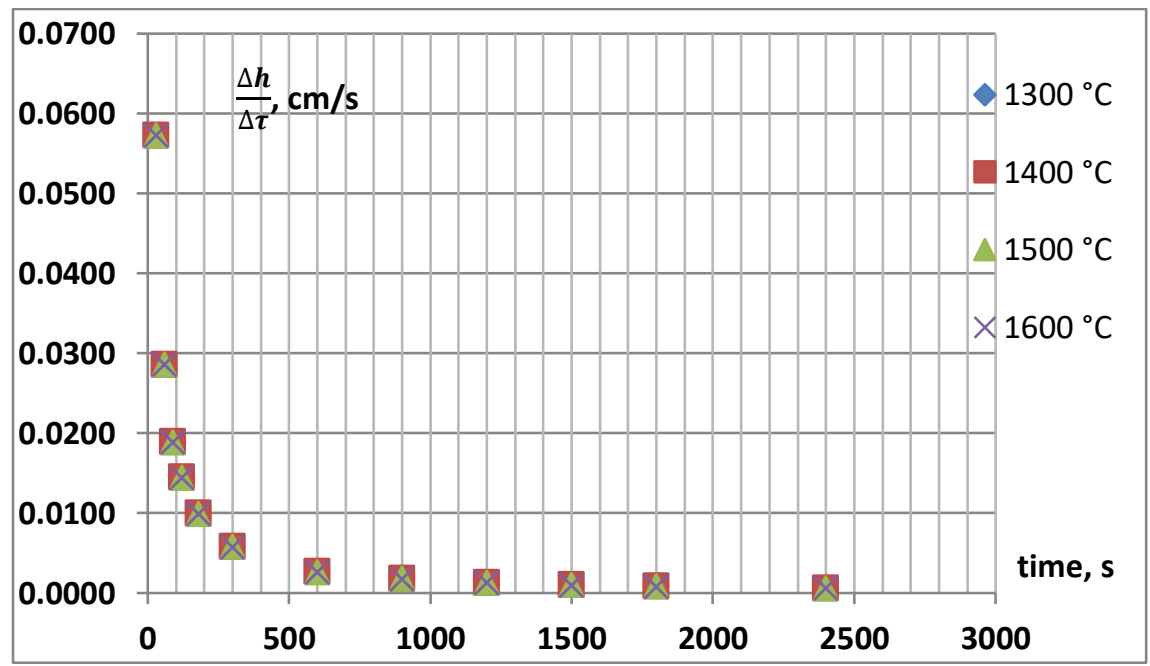

Figure 9. The dependence of the dissolution rate of lime samples on the dissolution time.

The relation between the linear rate of samples dissolution $\frac{\Delta h}{\Delta \tau}$ and the saturation concentration of $\mathrm{CaO}$ in slag has been derived (see Figure 10). With the increasing concentration of $\mathrm{CaO}$ in the slag the dissolution rate of samples drops which is due to the decrease in the concentration gradient $(\mathrm{CaO} \%)_{\text {sat }}-(\mathrm{CaO} \%)$.

The mass transfer coefficient values of lime dissolution in model slag calculated based on the experimental data are presented in (Figure 11). Mass transfer coefficients raise up to a certain value until the saturation of slag with lime. Furthermore, calculations showed lower values compared to pure $\mathrm{CaO}$ dissolution. Industrial lime contains magnesium oxide which reacts with slag forming solid compounds around lime particles and in turn inhibits the dissolution process.

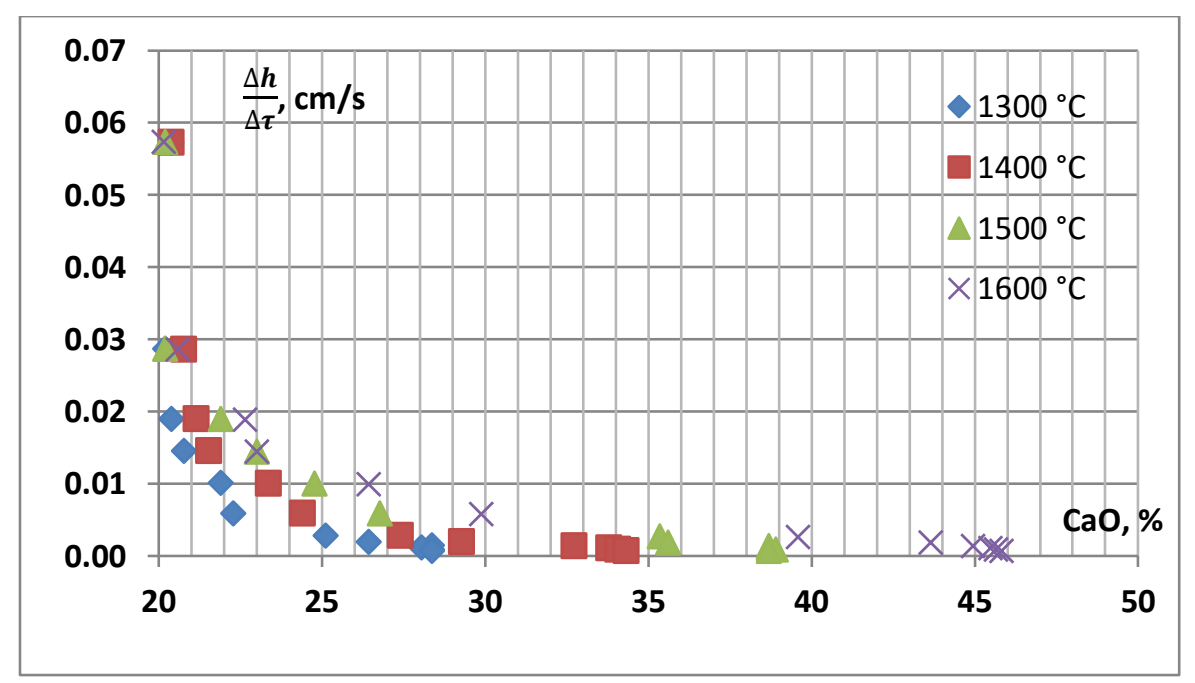

Figure 10. The dependence of the dissolution rate of lime samples on the calcium oxide concentration in slag. 


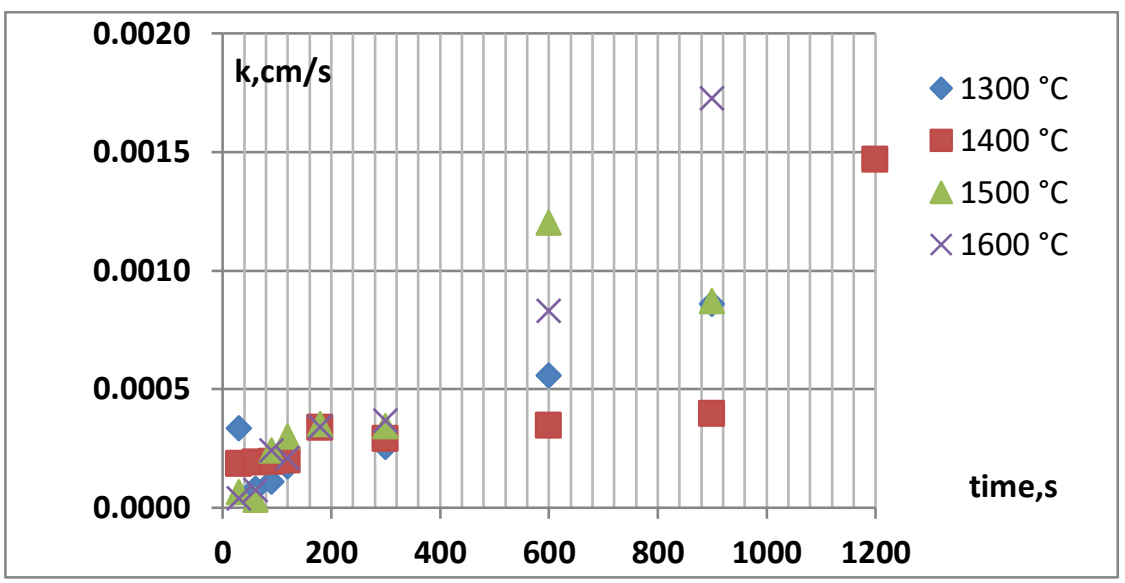

Figure 11. Calculated mass transfer coefficients of lime containing $2 \% \mathrm{MgO}$.

Table 3. Effective saturation concentration of $\mathrm{CaO}$ in slag phase for industrial lime

\begin{tabular}{|cccc|}
\hline \multicolumn{4}{|c|}{$\begin{array}{c}\text { Saturation concentration of } \mathrm{CaO} \text { in the slag, \% at given } \\
\text { temperatures }{ }^{\circ} \mathbf{C}\end{array}$} \\
\hline 1300 & 1400 & 1500 & 1600 \\
\hline $28.3-28.4$ & $34.0-34.3$ & $38.2-38.6$ & $45.5-45.8$ \\
\hline
\end{tabular}

The following (Equation 2) was applied to calculate diffusion coefficients and represents the linear form of Fick's second law for non-stationary spatial diffusion:

$$
w=\sqrt{\frac{D}{\pi}} \frac{c}{\sqrt{t}}+\frac{D c}{r},
$$

where $\mathrm{w}$ is the rate of diffusion; $r$ is the radius of diffusion propagation (sphere); $\mathrm{C}$ is the $\mathrm{CaO}$ concentration in the slag, $\mathrm{mol} / \mathrm{m}^{3}$.

Considering the mass of reacted substance in time interval, the diffusion coefficient of lime was determined. The detailed description of model was given in the previous work. [4]

The linear dependence of mass rate of calcium oxide samples $w=\frac{1}{s} \frac{d M}{d t}$ on the concentration variable $\frac{c}{\sqrt{t}}$ is presented in (Figure12). Diffusion coefficient values in the molten slag were calculated using the tangent of the angle and are presented in (Table 4).

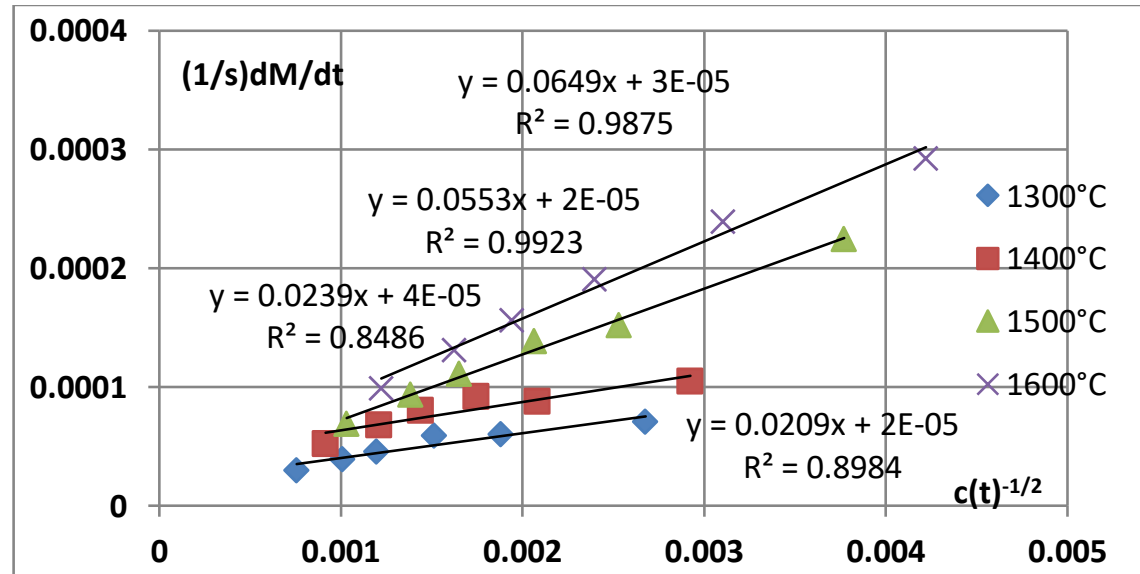

Figure 12. The dependence of the dissolution rate of lime samples containing $2 \%$ of $\mathrm{MgO}$ on the value of $\frac{c}{\sqrt{t}}$. 
Table 4. Calculated diffusion coefficients for given temperatures

\begin{tabular}{|c|cccc|}
\hline \multirow{3}{*}{$\mathbf{D}, \mathbf{c m}^{2} / \mathbf{s}$} & \multicolumn{4}{|c|}{ Temperature, ${ }^{\circ} \mathbf{C}$} \\
\cline { 2 - 5 } & 1300 & 1400 & 1500 & 1600 \\
\cline { 2 - 5 } & $1.37 \cdot 10^{-3}$ & $2.64 \cdot 10^{-3}$ & $9.6 \cdot 10^{-3}$ & $1.32 \cdot 10^{-2}$ \\
\hline
\end{tabular}

$1 / \mathrm{T},{ }^{\circ} \mathrm{C}^{-1}$

$\begin{array}{llllllll}0.00052 & 0.00054 & 0.00056 & 0.00058 & 0.0006 & 0.00062 & 0.00064 & 0.00066\end{array}$

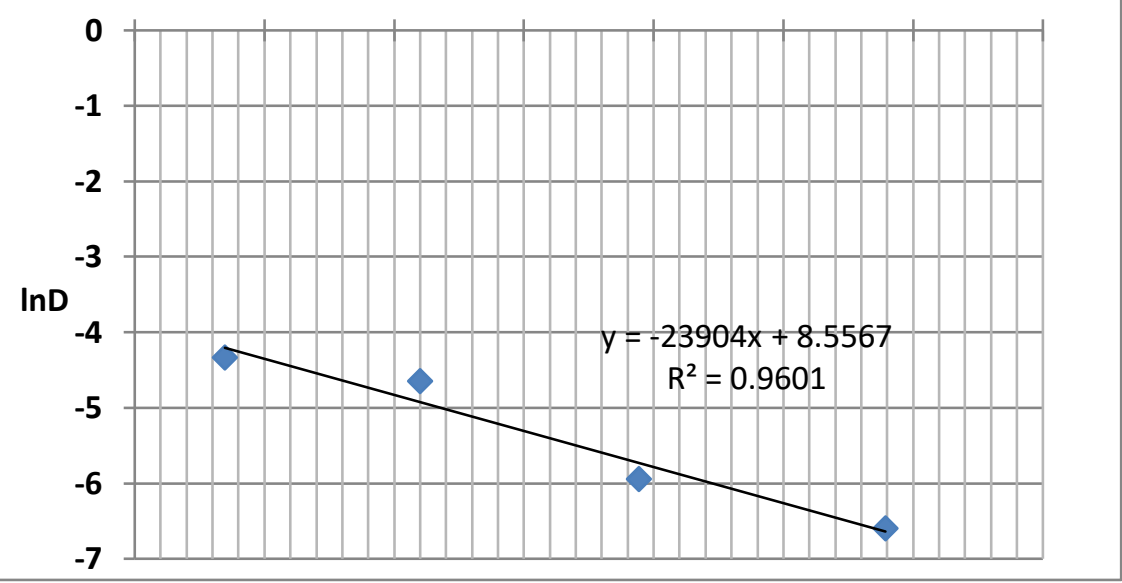

Figure 13. The dependence of the logarithm of the diffusion coefficient on the inverse temperature.

The linear correlation between logarithm of diffusion coefficient and inverse temperature (Figure 13) was derived and the diffusion activation energy was calculated: $198.7 \pm 17.0 \mathrm{~kJ} / \mathrm{mol}$. High diffusion activation energy value agrees with values reported in the literature and indicates the energy consumption of the system to bring the reactant atoms to the reaction site. [6]

\section{CONCLUSION}

The dissolution kinetics of pure calcium oxide and lime in liquid $\mathrm{CaO}-\mathrm{SiO}_{2}-\mathrm{FeO}$ and in industrial BOF slag at temperatures of $1300-1600^{\circ} \mathrm{C}$ has been studied. Effective mass transfer coefficients of $\mathrm{CaO}$ were derived based on kinetic model for solids dissolution in the liquid slag, and the total mass balance of the dissolving reagent.

It was found that the process of pure $\mathrm{CaO}$ and lime dissolution is diffusion- controlled. Furthermore, it was shown that industrial lime dissolution requires longer time and resulted in lower mass transfer coefficient values than pure $\mathrm{CaO}$. Formation of chemical compounds with magnesium oxide contained in the industrial lime was suggested to be the reason for the lower dissolution rate.

Diffusion coefficients were calculated using the experimental data under the conditions of non-stationary diffusion. The linear dependence of diffusion coefficients logarithm on the inverse temperature has been derived. The diffusion activation energy was calculated with the value of $198.7 \pm 17.0 \mathrm{~kJ} / \mathrm{mol}$.

\section{Acknowledgments}

Financial support is gratefully acknowledged by $\mathrm{K} 1$-Met. $\mathrm{K} 1-$ Met is the member of COMET - Competence Centers for Excellent Technologies and is financially supported by the Austrian ministers BMVIT and, BMVITJ, the provinces of Upper Austria, Styria and Tyrol, SFG and Tiroler Zukunftsstiftung. COMET is managed by FFG (Austrian research promotion agency). 


\section{REFERENCES}

1 Dogan N, Brooks GA, and Muhhamad AR. Kinetics of flux dissolution in oxygen steelmaking. ISIJ International. 2009; 49: 1474-1482.

2 Deng T, Sichen D. Study of lime dissolution under forced convection. Metallurgical and Materials Transactions B. 2012; 43(3): 578.

3 Umakoshi M, Mori K, Kawai K. Dissolution rate of burned dolomite in molten $\mathrm{Fe}_{\mathrm{t}} \mathrm{O}-\mathrm{CaO}-$ $\mathrm{SiO}_{2}$ slags. Trans. Iron Steel Inst. Jpn. 1984; 24: 532.

4 Cheremisina E, Schenk J, Nocke L, Paul A, Wimmer G. Influence of magnesium oxide content on kinetics of lime dissolution in steelmaking slags. ISIJ International. 2017, 47(3): 304.

5 Fruehan RJ, Li Y, Brabie L. Dissolution of magnesite and dolomite in simulated EAF slags. ISS Tech Conference. 2003; 799-812.

6 Posin ME. Research in inorganic Technology. Moscow: Science; 1972. 